\title{
The Significance of Habitat Characteristics to the Spatial Distribution of Local Avian Assemblage at Gannoruwa Mountain Forest Reserve, Kandy, Sri Lanka
}

\author{
D. G. R. M. M. Kaushalya Rathnayake, ${ }^{1}$ I. Sandunika Ileperuma Arachchi, ${ }^{1}$ \\ Buwaneka S. Pathirana, ${ }^{2}$ and S. Wickramasinghe ${ }^{1}$ \\ ${ }^{1}$ Department of Biological Sciences, Faculty of Applied Sciences, Rajarata University of Sri Lanka, 50300 Mihintale, Sri Lanka \\ ${ }^{2}$ Postgraduate Institute of Agriculture, University of Peradeniya, 20400 Peradeniya, Sri Lanka
}

Correspondence should be addressed to D. G. R. M. M. Kaushalya Rathnayake; kaushdx@yahoo.com

Received 9 March 2016; Accepted 22 June 2016

Academic Editor: Alexandre Sebbenn

Copyright (C) 2016 D. G. R. M. M. Kaushalya Rathnayake et al. This is an open access article distributed under the Creative Commons Attribution License, which permits unrestricted use, distribution, and reproduction in any medium, provided the original work is properly cited.

\begin{abstract}
Distribution patterns corresponding to habitat characteristics in tropical forests have not been largely studied. Natural forest structure as well as the anthropogenic alterations to the forests equally affects the distribution patterns of wet zone avifauna. The study reveals the importance of \% canopy closure, distance from the forest edge, tree density, diversity, and elevation to the community composition of local forest birds inhabiting Gannoruwa Forest Reserve, Sri Lanka. The most important factors resulting in the study for shaping the avian distribution pattern are distance from the edge,elevation, and the \% canopy closure. With the increase of favouring resources to the avian fauna at the edges and the juxtaposition of the edge, many forest loving species were observed to move towards the edge. The pattern is proven advantageous, but harmful in the long run. Thus, it is advisable that the conservation plans should focus on habitat destruction and the anthropogenic disturbance along forest edges.
\end{abstract}

\section{Introduction}

Continuous conversion of forests for agricultural purposes and urban development has increased rapidly in the last two decades [1]. Most recent studies have confirmed that the avian diversity declines rapidly with this destruction of the forests [2-6].

Studies on the relationship between avifaunal communities and the habitat variables have recently become a major theme in ecological studies [7]. But most of the researches have been done in tropics confined to examine the effect on birds in urban-rural gradients [2, 8-10] or agroecosystems $[11,12]$. The focus on avifaunal distribution patterns in natural ecosystems seems to be less in literature. The scarcity of the knowledge on initial phases of the destruction and threats exerted on natural forest habitats diverts the attention of regional conservation planners from natural forest patches in early phases of destruction to severely destructed habitats and their regeneration. Vegetation structure along with the openness of the habitat is rapidly changing with the anthropogenic disturbance. As trees and shrubs have positive effect on avian biodiversity [11] continuous monitoring of the landscape changes may act as a surrogate for predicting community structure of fauna associated with the habitat.

A rapid urban development has taken place in vicinity of most remnant natural forests of Sri Lanka. The alteration of forests into farmlands, human settlements, and industrial lands brought chaos to the primary and secondary forests causing rapid declining of the total forest cover $[13,14]$ along with its faunal composition. Hence, the need for strong action plan to assess the status of rapidly diminishing forest patches and their faunal composition is rising at rapid pace. The knowledge gap should be filled with in-depth ecological studies on habitat alteration and community structure of fauna in order to strengthen the regional conservation plans.

By referring to the available literature, we have found that only a few studies have been conducted on the forest avian species distribution and key factors defining the patterns of 
the distribution in Sri Lanka. Here, in the present study, we report bird community composition and some major factors influencing their distribution across landscape in Gannoruwa Forest Reserve (GFR). Identifying and cataloguing the bird species living in GFR and understanding the local avian community structure and factors responsible for shaping of their spatial distribution pattern across the landscape were among the major objectives of this study. Ultimately authors seek to emphasize the importance of conserving these small forest patches in order to conserve local avian assemblages.

Gannoruwa Forest Reserve is one of the remaining remnant forest ecosystems in the Kandy district, found closer to the world famous Royal Botanical Garden of Peradeniya. In addition to ecological value of this forest reserve, it bears historical and cultural importance being located in the area where the famous Gannoruwa battle has taken place victoriously defeating a Portuguese army led by Diogo de Melo de Castro by Sinhalese King's army in 1638. Historical and biogeographical evidences support the fact that Gannoruwa forest had been connected to other remnant forests in the region, namely, Udawatta Kele, Hanthana Mountain Range, Waakarawaththa Forest, and Bahirawa Kanda Mountain forming a continuous range of forest. This forest has been subjected to several controversies due to its mixed nature in floristic composition [15, 16]. GFR is identified as an ideal place to study the wet zone avifauna though very little work has been done in this regard. Currently this unique forest patch is under threat due to illegal anthropogenic activities such as poaching, logging, and burning which push its biodiversity to imminent danger.

As a biodiversity hotspot Sri Lanka holds rich avifaunal diversity with approximately 453 species, including 237 breeding residents and 216 migrants of which 72 species are vagrants or accidental visitors [17-20]. Moreover, Sri Lanka hosts 27 avian endemic species, with six species under consideration for specific recognition $[17,19,20]$. A considerable number of avian species are categorized as forest species [21] and majority of them are frequently observed in northwestern wet zone and central highlands [14]. Thus, forest patches located in the vicinity of Kandy city bear the importance of being avifaunal hotspots of wet zone. Hence this area was categorized as a hill country avifaunal zone in biodiversity action plan in 1995. Biodiversity survey conducted by Basnayake et al. [15] recorded 76 bird species belonging to 60 genera and to 32 families with seven endemic species. The present study holds the importance of being the first study carried out on an ecological aspect of avian community in GFR and here we report the variation in avian biodiversity in different habitat types in GFR.

\section{Methods}

2.1. Study Site. GFR is a hill rainforest located approximately $6.5 \mathrm{~km}$ southwest of the Kandy city, Sri Lanka $\left(7^{\circ} 17^{\prime} \mathrm{N}\right.$, $80^{\circ} 36^{\prime} \mathrm{E}$ ). The extent of the forest is about $1.2 \mathrm{~km}^{2}$ and a part of it is covered with a Mahogany (Swietenia macrophylla) plantation. The mean elevation of the GFR varies between $600 \mathrm{~m}$ and $750 \mathrm{~m}$, though few points rise above $750 \mathrm{~m}$. The forest area mainly consists of rocky habitats. Main rock types belong to Precambrian metamorphic rocks and unduly distributed quartzite and dolomite can be seen in-between these rocky habitats [22]. This area receives $2100 \mathrm{~mm}$ of annual rainfall, which is evenly distributed throughout the year. Despite the slight changes in temperature, mean annual temperature of the forest ecotone is $24^{\circ} \mathrm{C}$. The area belongs to the KandyUpper Mahaweli Floristic Zone [23] and intermediate wet evergreen forest ecotone [15]. The northwestern area of the forest is an abandoned coffee plantation that was cultivated during the colonial time. On the western flank of the mountain, there is emerging grassland that has been established due to frequent fires set by the villagers at the forest boundary. There are no perennial streams found inside the forest but few seasonal streams are present at rainy seasons. However the mountain acts as a watershed, providing water for the villagers.

2.2. Survey Methods and Data Analysis. Birds were surveyed using a point counting method $[2,24]$. Four parallel beltstransects were set up from the forest edge with the help of a GPS receiver (Garmin GPS 72H, 2009, Garmin International, Inc., Kansas, USA). Elevational levels of transects were (A) forest edge $=557.2 \mathrm{~m}-558.5 \mathrm{~m}$, (B) edge forest transitional habitat $=562.7 \mathrm{~m}-567.3 \mathrm{~m},(\mathrm{C})$ forest interior $=$ $584.8 \mathrm{~m}-592.73 \mathrm{~m}$, and (D) Mahogany plantation at summit = $610.0 \mathrm{~m}-632.76 \mathrm{~m}$. Each was $500 \mathrm{~m}$ in length and four points were established on each transect with the distance $100 \mathrm{~m}$ between each of the two points. The visibility range inside the forest patch was less than $75 \mathrm{~m}$ to the naked eye in lower altitudes, due to dense undergrowth. Thus, the distance between observation points could be justified and the error of double counting of birds in several points could be considered as negligible. All four transects were $500 \mathrm{~m}$ apart from each other. Twenty- one bird survey rounds were operated covering the whole breeding season: end of December 2013, end of May, and the end of June in 2014. One survey round per week was conducted. One survey round consisted of two walks in all four transects. Each survey session was conducted in clear and dry weather conditions, avoiding heavy rains and windy days from $0800 \mathrm{~h}$ to $1000 \mathrm{~h}$ and from $1600 \mathrm{~h}$ to $1800 \mathrm{~h}$. Data were gathered for 30 minutes in each transect. All the birds were noted via listening to their distinctive calls and sighting while standing still in the middle of the sampling point. Birds flying above the sampling points were not counted to prevent producing the error of double counting in the next sampling point. Also, when recording species encountered around the sampling point, all birds that flew over about $100 \mathrm{~m}$ from the observer [25] and detections that fell within the adjacent transects were excluded [8]. Three night surveys were conducted around the periphery of the GFR and on the transect $\mathrm{B}$ to assess the diversity of nocturnal birds. Birds encountered in field studies were identified using available guides $[19,21,26]$. The total number of birds detected in each of the four observation plots in belt transects was counted and this number was referred to as "observed" species richness [25]. Avian diversity in tropical wet zone forests is rarely estimated directly as many cryptic species may be always obscured from observations due to foliage cover. Some species may not be observed or heard in survey rounds as 
TABLE 1: The results of avifaunal community assessment in four different habitats along the elevational gradient in GFR.

\begin{tabular}{lcccccc}
\hline Habitat type & $\begin{array}{c}\text { Elevational level } \\
\text { from MSL meters }\end{array}$ & $\begin{array}{c}\text { Distance from } \\
\text { edge meters }\end{array}$ & $\begin{array}{c}\text { Total number } \\
\text { of birds } \\
\text { observed }\end{array}$ & $\begin{array}{c}\text { Number of } \\
\text { species per point } \\
\text { (mean } \pm \text { SE) }\end{array}$ & $\begin{array}{c}\text { Observed richness } \\
\text { (mean } \pm \text { SE) }\end{array}$ & $\begin{array}{c}\text { Shannon Wiener Diversity } \\
\text { Index (mean } \pm \text { SE) }\end{array}$ \\
\hline $\begin{array}{l}\text { Forest edge } \\
\begin{array}{l}\text { Edge forest } \\
\text { transitional habitat }\end{array}\end{array}$ & $557.2-558.5$ & 0 & 1537 & $17 \pm 0.52$ & $70 \pm 1.12$ & $3.550 \pm 0.03$ \\
$\begin{array}{l}\text { Forest interior } \\
\begin{array}{l}\text { Mahogany } \\
\text { plantation at summit }\end{array}\end{array}$ & $584.7-567.3$ & $504 \pm 2$ & 657 & $14 \pm 0.35$ & $56 \pm 2.61$ & $3.724 \pm 0.03$ \\
\hline
\end{tabular}

their vocal activity periods will not overlap with the survey periods. Thus, the overall diversity of avian assemblages in the forest ecosystem and in each belt transect was calculated using the jackknife estimate of Shannon Wiener Diversity Index $\left(H^{\prime}\right)$ to correct the observation biases [27].

To describe the vegetation structure of the different elevational levels of mountain forest, $20 \mathrm{~m}$ radius circular plot sampling method was followed. Five circular plots per one transect were laid and altogether 20 circular plots were analyzed to determine the nature of vegetation in each transect. All trees presented within $20 \mathrm{~m}$ radius circular plot with diameter at breast height $(\mathrm{dbh})$ more than $5 \mathrm{~cm}$ were identified and counted. Tree densities in each transect were calculated by counting and averaging trees with $>5 \mathrm{~cm} \mathrm{dbh}$ in $410 \mathrm{~m} \times 10 \mathrm{~m}$ quadrates laid on each transect. Relative canopy cover values of the sampling points were assessed by analyzing digital canopy photographs taken by a camera placed high in $3 \mathrm{~m}$ from the forest floor. Digital photographs were converted to binary images so that canopy closure was shown in black while open sky is in white. Percentage of closure can be estimated by calculating proportion of black pixels in the image [28]. Canopy closure values were pooled and tested for significant difference in four elevational levels using one-way analysis of variance (ANOVA) using Minitab v.16 statistical package.

Comparisons of vegetation composition and avian fauna arrayed in four elevational levels were done in community level. One-way ANOVA test is performed following Tukey's test to confirm the heterogeneity of the vegetation density and diversity. Morisita's dissimilarity index was used to compare each of the four communities of avian fauna. Calculations were performed in SPADE data analysis tool developed by Chao and Shen (2010) [29]. Standard multiple regression test was conducted using Bonferroni adjusted alpha level [30] of 0.01 per test $(0.05 / 5)$ for five landscape variables to assess which landscape variables (stand density, tree diversity, percentage canopy closure, elevation, and distance from the edge) were significantly correlated with (1) avifaunal diversity, (2) avifaunal richness, and (3) species density in transects laid in GFR [8].

\section{Results}

3.1. Bird Richness and Diversity. A total of 3110 individual birds belonging to 84 species belonging to 38 families were counted from all point count stations. During the study period eleven endemic species were recorded in the GFR including yellow-fronted barbet (Megalaima flavifrons), Sri Lanka grey hornbill (Ocyceros gingalensis), Sri Lanka hanging-parrot (Loriculus beryllinus), emerald-collared parakeet (Psittacula calthropae), Sri Lanka wood pigeon (Columba torringtoniae), spot winged thrush (Zoothera spiloptera), dull blue flycatcher (Eumyias sordidus), Sri Lanka myna (Gracula ptilogenys), brown-capped babbler (Pellorneum fuscocapillus), Sri Lanka scimitar-babbler (Pomatorhinus melanurus), and Sri Lanka junglefowl (Gallus lafayetii). Further, six proposed endemic species were also recorded from the study area namely, greater flameback (Chrysocolaptes lucidus), crimson-fronted barbet (Megalamia rubricapillusru bricapillus), pompadour green pigeon (Treron pompadora pompadora), black-crested bulbul (Pycnonotus melanicterus), redrumped swallow (Hirundo hyperythra), and common woodshrike (Tephrodornis pondicerianus affinis). The endemicity is shown to be high and nearly $40 \%$ of endemic bird species of Sri Lanka were found within the habitat.

The area has become an important habitat as it provides habitats for five species which are categorized as vulnerable and one species was categorized as endangered in the national red list of Sri Lanka [20]. The species categorized as vulnerable are the Sri Lanka wood pigeon, Sri Lanka spot winged thrush, Sri Lanka dull blue flycatcher, Sri Lanka myna, and hill swallow (Hirundo domicola) while the common kestrel (Falco tinnunculus) was recorded as endangered species.

Of the 85 species of birds recorded, 70 species were recorded at the lower mountain edge, whereas 36 bird species were recorded in edge forest transitional habitats. The lowest number of bird species was recorded from thick forest habitats (39 species) and Mahogany (Swietenia macrophylla) plantation at the summit of the mountain ( 45 species). Forest edge and transitional habitats harbor highest number of species per point in transect while the forest interior harbors the least. Forest interior habitats bear a low number of avian species and it is considerably lower than the forest edge (see Table 1). Avian diversity was highest at edge forest transitional habitats and forest edge while the diversity recorded in forest interior was the least (Table 1). Despite the uniform nature of the vegetation, Mahogany plantation was shown to attract many bird species more than the other habitats maybe because open spaces create high visibility for birds who hunt small invertebrates and mammals. There was a significant difference in avifaunal diversities calculated for four habitats as determined by one-way ANOVA $(p<0.035)$. The avian 
TABLE 2: Vegetation characteristics of different habitats along the elevational gradient in GFR.

\begin{tabular}{lcccc}
\hline Vegetation character & Forest edge & $\begin{array}{c}\text { Edge forest } \\
\text { transitional habitat }\end{array}$ & Forest interior & Mahogany plantation at summit \\
\hline Tree density $\left(\right.$ per $\left.100 \mathrm{~m}^{2}\right)$ & $112 \pm 14$ & $269 \pm 13$ & $208 \pm 09$ & $92 \pm 04$ \\
Tree diversity $\left(H^{\prime}\right)$ & $2.137 \pm 0.11$ & $2.858 \pm 0.58$ & $2.506 \pm 0.04$ & $2.038 \pm 0.72$ \\
$\%$ canopy closure & $37.19 \pm 6.92$ & $81.61 \pm 2.72$ & $73.77 \pm 6.71$ & $67.03 \pm 4.20$ \\
\hline
\end{tabular}

community in the forest interior showed the highest dissimilarity to the avian community residing in edge habitats $\left(C_{i j}=\right.$ 0.712). Two nationally vulnerable species (Sri Lanka wood pigeon, Sri Lanka Myna) were recorded to share those habitats. Least dissimilarity was reported between communities of edge forest transitional habitats and Mahogany plantations at the summit $\left(C_{i j}=0.48\right)$. Many avian species were reported to actively share these habitats for breeding and forage (see Supplementary Table 4 in Supplementary Material available online at http://dx.doi.org/10.1155/2016/8148910).

3.2. Vegetation Characteristics. Statistical analysis of vegetation attributes showed that the tree density is higher at the forest edge transitional habitats and interior habitats (Table 2). As primarily being a monoculture, Mahogany plantation at summit bears least tree density despite several other plant species grown among Mahogany plants. This observation explains the vegetation diversity in four habitats. As vegetation density and diversity are higher at the edge forest transitional habitats canopy closure was expected to be highest. Percentages of canopy closure were significantly different in four habitats $(p<0.04)$.

\subsection{Species-Habitat Characteristics Relationship. From} assessed habitat structural variables, distance from the edge was shown to have strong significant negative effect on avifaunal richness and density (Table 3 ) while contributing weakly to defining avifaunal diversity in the habitat. Tree density and diversity tend to be negatively correlated with avifaunal richness and density at a given point and positively correlated with avifaunal diversity. However, the elevation exhibits exerting a strong negative effect on defining avian community structure in GFR by having significant relationships with avifaunal richness and the density.

\section{Discussion and Conclusions}

In general, GFR supports the higher number of wet zone breeding resident bird species and some migratory species. Altogether we observed 85 species of birds. This number is expected to increase with ongoing avifaunal survey in the northern flank of the forest.

Clear distinguishable patterns are observed to be emerging in the responses of avian community structure to habitat characteristics in study, and undoubtedly this variation resulted in avian assemblages specific to the degree of anthropogenic distribution along the elevational gradient of the forest [8]. At forest edge and the juxtaposition of the edge support higher number of avian species than the other interior
TABLE 3: The relationship between different habitat characteristics and avifaunal community attributes (Bonferroni adjusted alpha level $=0.01)$.

\begin{tabular}{lcc}
\hline Habitat characteristics & $r$ & $p$ \\
\hline Avifaunal diversity & & \\
Elevation & -0.305 & 0.335 \\
Tree density & 0.126 & 0.696 \\
Tree diversity & 0.164 & 0.61 \\
\% canopy closure & -0.176 & 0.585 \\
Distance from the edge & -0.231 & 0.470 \\
Avifaunal richness & & \\
Elevation & -0.821 & 0.001 \\
Tree density & -0.223 & 0.486 \\
Tree diversity & -0.108 & 0.739 \\
\% canopy closure & -0.546 & 0.047 \\
Distance from the edge & -0.802 & 0.002 \\
Avifaunal density & & \\
Elevation & -0.651 & 0.022 \\
Tree density & -0.223 & 0.486 \\
Tree diversity & -0.193 & 0.547 \\
\% canopy closure & -0.509 & 0.031 \\
Distance from the edge & -0.788 & 0.000 \\
\hline
\end{tabular}

habitat. Despite the anthropophilic species such as brownheaded barbet, red-vented bulbul, and yellow-billed babbler $[26,31]$ some forest loving birds such as Sri Lanka wood pigeon and emerald-collared parakeet [21] were observed to actively utilize resources available in these habitats. Although these observations are from our area of study, avian assemblages were typical to other neighborhood study systems available in literature $[15,32,33]$.

The most important factors influencing avifaunal community structure were elevation, distance from the edge, and the canopy closure. Being negatively correlated with avian diversity, richness, and density it is expected to increase the tendency of avifauna to move towards the edges of the forest. Forest edge transitional habitats bear high percentage canopy cover and are observed to attract many bird species (see supplementary material). Majority of nesting birds were observed in this near edge habitat while many cavity breeders were observed at edge habitats. The reason may be the shade and food resources created by vegetation complexity and the optimum environmental conditions like light and wind [34]. However, though this tendency is advantageous for birds in community, the long-lasting survival will be at risk because the edges may expose birds to a variety of negative impacts, 
including increased predation and competition along edges. The expansion of hamlets towards the forest will be destructing the breeding grounds of edge inhabitants making them losers in expanding edges $[8,35]$.

The Mahogany plantation at the summit does not create considerable canopy closure and it is generally considered as an open area. And the homogeneous nature of the vegetation does not seem to attract many bird species compared to few raptors and insectivores.

The tree density of the forest did not exhibit a strong relationship with avifaunal community composition. The positive and weak relationships between tree density and avifaunal diversity support the fact that many birds prefer to reside in places where there are dense stands of trees to open areas. Thus, more studies should be carried out to rule out valid reasons to this exhibited pattern. Additionally, the positive and weak relationships with avifaunal richness and tree density also support the above fact that the higher number of birds tends to flock in dense forest habitats than less dense forest habitats.

4.1. Conservation Issues. Our study suggests that this forest patch is very rich in avian biodiversity. The protected Hanthana Mountain Range is situated next to this forest patch. Therefore, the local migration of avian fauna from Hanthana can be suspected to have an effect on this rich avian biodiversity and we are proposing to have further study in this regard to reach a confirmed decision.

Apart from that, a variety of ecological characteristics are helping to determine the avian assemblages in the landscape. These characteristics were shaped not only by natural processes but also through anthropogenic activities. Therefore, the conservation issues clearly began to emerge regarding safeguarding the forest reserve with its inhabiting flora and fauna.

Habitat destruction by frequent fire on the western flank of the forest, poaching, expanding human settlements toward the forest, and deforestation are among the major threats to the forest. Unrestricted access to the forest allowed to the villagers, hiking groups, and many types of visitors causes huge disturbances to the ecotone bird species. As many cavity breeders are nesting in the trees at the edges of the forest, expansion of hamlets towards the forest causes destruction of breeding grounds of edge species such as the endemic and nationally vulnerable Sri Lanka Myna.

As this study reveals an increase of avian diversity of the forest since the last known records from 1998, a long term monitoring program should be implemented to identify the changes of species composition with vegetation changes and anthropogenic activities and to track changes in habitat preferences of ecotone birds. This will help in formulating conservation and management plan for the GFR.

To conserve this mountain bird paradise, increasing awareness about the value of the forest and enforcing legal actions against those who destroy the habitat are suggested. The program can strengthen further with the help of the surrounding community, local environmentalists, and other stakeholders such as conservation societies and school children.

\section{Competing Interests}

The authors declare no conflict of interests.

\section{Authors' Contributions}

D. G. R. M. M. Kaushalya Rathnayake, I. Sandunika Ileperuma Arachchi, and Buwaneka S. Pathirana carried out this study and contributed to designing the research and formulating the relevant data analysis. D. G. R. M. M. Kaushalya Rathnayake undertook the responsibility for drafting the paper and was ably supported by the coauthors in study designing and carrying out the data analysis portion as well as the paper revision. All authors read and approved the final manuscript. D. G. R. M. M. Kaushalya Rathnayake, I. Sandunika Ileperuma Arachchi, Buwaneka S. Pathirana, and S. Wickramasinghe contributed equally to this work.

\section{Acknowledgments}

Special thanks go to Ashanka Bulathgama, Pulasthi Pathirana (PGIA, University of Peradeniya), and Viraj Rathnayake for helping the authors with fieldworks and Nuwanjith Ulpathakumbura (Rajarata University of Sri Lanka) for helping them to take photographs of birds during field studies. Kanishka Ukuwela (RUSL) and M. T. H. M. Shaheed (TSEP/OMSU) are greatly acknowledged for the support given in producing this paper.

\section{References}

[1] M. C. Hansen, P. V. Potapov, R. Moore et al., "High-resolution global maps of 21st-century forest cover change," Science, vol. 342, no. 6160, pp. 850-853, 2013.

[2] P. Batáry, S. Fronczek, C. Normann, C. Scherber, and T. Tscharntke, "How do edge effect and tree species diversity change bird diversity and avian nest survival in Germany's largest deciduous forest?" Forest Ecology and Management, vol. 319, pp. 44-50, 2014.

[3] M. L. Cadenasso and S. T. A. Pickett, "Effect of edge structure on the flux of species into forest interiors," Conservation Biology, vol. 15, no. 1, pp. 91-97, 2001.

[4] J. Holloway, “The impact of traditional and modern cultivation practices, including forestry, on lepidoptera diversity in Malaysia and Indonesia," in Dynamics of tropical communities : the 37th symposium of the British Ecological Society, Cambridge University, 1996, D. Newbery, H. Prins, and N. Brown, Eds., pp. 567-597, Blackwell Science, 1998.

[5] S. Pimm, P. Raven, A. Peterson, Ç. H. Şekercioğlu, and P. R. Ehrlich, "Human impacts on the rates of recent, present, and future bird extinctions," Proceedings of the National Academy of Sciences of the United States of America, vol. 103, no. 29, pp. 10941-10946, 2006.

[6] R. H. Yahner, "Changes in wildlife communities near edges," Conservation Biology, vol. 2, no. 4, pp. 333-339, 1988. 
[7] P. Clergeau, J.-P. L. Savard, G. Mennechez, and G. Falardeau, "Bird abundance and diversity along an urban-rural gradient: a comparative study between two cities on different continents," Condor, vol. 100, no. 3, pp. 413-425, 1998.

[8] K. R. Crooks, A. V. Suarez, and D. T. Bolger, "Avian assemblages along a gradient of urbanization in a highly fragmented landscape," Biological Conservation, vol. 115, no. 3, pp. 451-462, 2004.

[9] L. Díaz, "Influences of forest type and forest structure on bird communities in oak and pine woodlands in Spain," Forest Ecology and Management, vol. 223, no. 1-3, pp. 54-65, 2006.

[10] P. Matson, "Special feature: the use of urban gradients in ecological studies," Ecology, vol. 71, no. 4, p. 1231, 1990.

[11] I. Laube, N. Breitbach, and K. Böhning-Gaese, "Avian diversity in a Kenyan agroecosystem: effects of habitat structure and proximity to forest," Journal of Ornithology, vol. 149, no. 2, pp. 181-191, 2008.

[12] J. Vandermeer, M. Van Noordwijk, J. Anderson, C. Ong, and I. Perfecto, "Global change and multi-species agroecosystems: concepts and issues," Agriculture, Ecosystems and Environment, vol. 67, no. 1, pp. 1-22, 1998.

[13] C. Bambaradeniya, M. Perera, W. Perera et al., "Composition of faunal species in the Sinharaja world heritage site in Sri Lanka," 2003.

[14] D. E. Gabadage, W. M. S. Botejue, T. D. Surasinghe et al., "Avifaunal diversity in the peripheral areas of the Maduruoya National Park in Sri Lanka: with conservation and management implications," Journal of Asia-Pacific Biodiversity, vol. 8, no. 2, pp. 121-132, 2015.

[15] B. M. K. M. K. Basnayake, Biodiversity of Gannoruwa Forest and Its Sustainable Management, University of Peradeniya, Peradeniya, Sri Lanka, 1998.

[16] W. M. N. Weerasekara, Assessing the Diversity of Woody Plant Species in Gannoruwa Forest and Preparation of Simple Teaching Aid for Teaching Ecological Diversity, University of Peradeniya, Peradeniya, Sri Lanka, 1999.

[17] S. W. Kotagama, R. I. De Silva, A. S. Wijayasinha, and V. Abeygunawardane, "Avifaunal list of Sri Lanka," in Fauna of Sri Lanka: Status of Taxonomy, Research and Conservation, C. N. B. Bambaradeniya, Ed., pp. 164-203, The World Conservation Union, Colombo, Sri Lanka, 2006.

[18] P. C. Rasmussen and J. C. Anderton, Birds of South Asia: The Ripley Guide, Smithsonian Institution, Washington, DC, USA, 2005.

[19] D. Warakagoda and U. Sirivardana, “The avifauna of Sri Lanka: an overview of the current status," TAPROBANICA: The Journal of Asian Biodiversity, vol. 1, pp. 28-35, 2009.

[20] D. K. Weerakoon and K. Gunawardena, "The taxonomy and conservation status of birds in Sri Lanka," in The National Red List 2012 of Sri Lanka, pp. 114-133, 2012.

[21] J. Harrison, A Field Guide to the Birds of Sri Lanka, Oxford University Press, New York, NY, USA, 2011.

[22] P. G. Cooray and P. Cooray, An Introduction to the Geology of Ceylon, vol. 31, National Museums of Ceylon, Colombo, Sri Lanka, 1967.

[23] M. S. Ashton, S. Gunatilleke, N. De Zoysa, M. Dassanayake, N. Gunatilleke, and S. Wijesundera, A Field Guide to the Common Trees and Shrubs of Sri Lanka, WHT Publications, Colombo, Sri Lanka, 1997.

[24] C. J. Bibby, N. D. Burgess, and D. A. Hill, Bird Census Techniques, Academic press, Cambridge, Mass, USA, 2012.
[25] M. Waltert, K. S. Bobo, N. M. Sainge, H. Fermon, and M. Mühlenberg, "From forest to farmland: habitat effects on afrotropical forest bird diversity," Ecological Applications, vol.15, no. 4, pp. 1351-1366, 2005.

[26] G. M. Henry, A Guide to the Birds of Sri Lanka, Oxford University Press, New York, NY, USA, 1998.

[27] F. Babweteera and N. Brown, "Can remnant frugivore species effectively disperse tree seeds in secondary tropical rain forests?" Biodiversity and Conservation, vol. 18, no. 6, pp. 1611$1627,2009$.

[28] L. Korhonen, K. T. Korhonen, M. Rautiainen, and P. Stenberg, "Estimation of forest canopy cover: a comparison of field measurement techniques," Silva Fennica, vol. 40, no. 4, pp. 577588, 2006.

[29] A. Chao and T. J. Shen, Program Spade (Species Prediction and Diversity Estimation). Program and User's Guide, 2010.

[30] Y. Hochberg, "A sharper Bonferroni procedure for multiple tests of significance," Biometrika, vol. 75, no. 4, pp. 800-802, 1988.

[31] W. V. Legge, A History of the Birds of Ceylon, Tisara Prakasakayo, Dehiwala, Sri Lanka, 2nd edition, 1983.

[32] K. Subasinghe, A. P. Sumanapala, and S. R. Weerawardhena, "The impact of forest conversion on bird communities in the northern flank of the Knuckles mountain forest range, Sri Lanka," Journal of Asia-Pacific Biodiversity, vol. 7, no. 4, pp. 367373, 2014.

[33] C. Wijesundara and M. Wijesundara, "Bird diversity of Dekinda forest reserve, Balana, Sri Lanka: implications for conservation," Ceylon Journal of Science (Biological Sciences), vol. 43, pp. 137146, 2014.

[34] C. Murcia, "Edge effects in fragmented forests: implications for conservation," Trends in Ecology \& Evolution, vol. 10, no. 2, pp. 58-62, 1995.

[35] M. L. McKinney and J. L. Lockwood, "Biotic homogenization: a sequential and selective process," in Biotic Homogenization, pp. 1-17, Springer, 2001. 

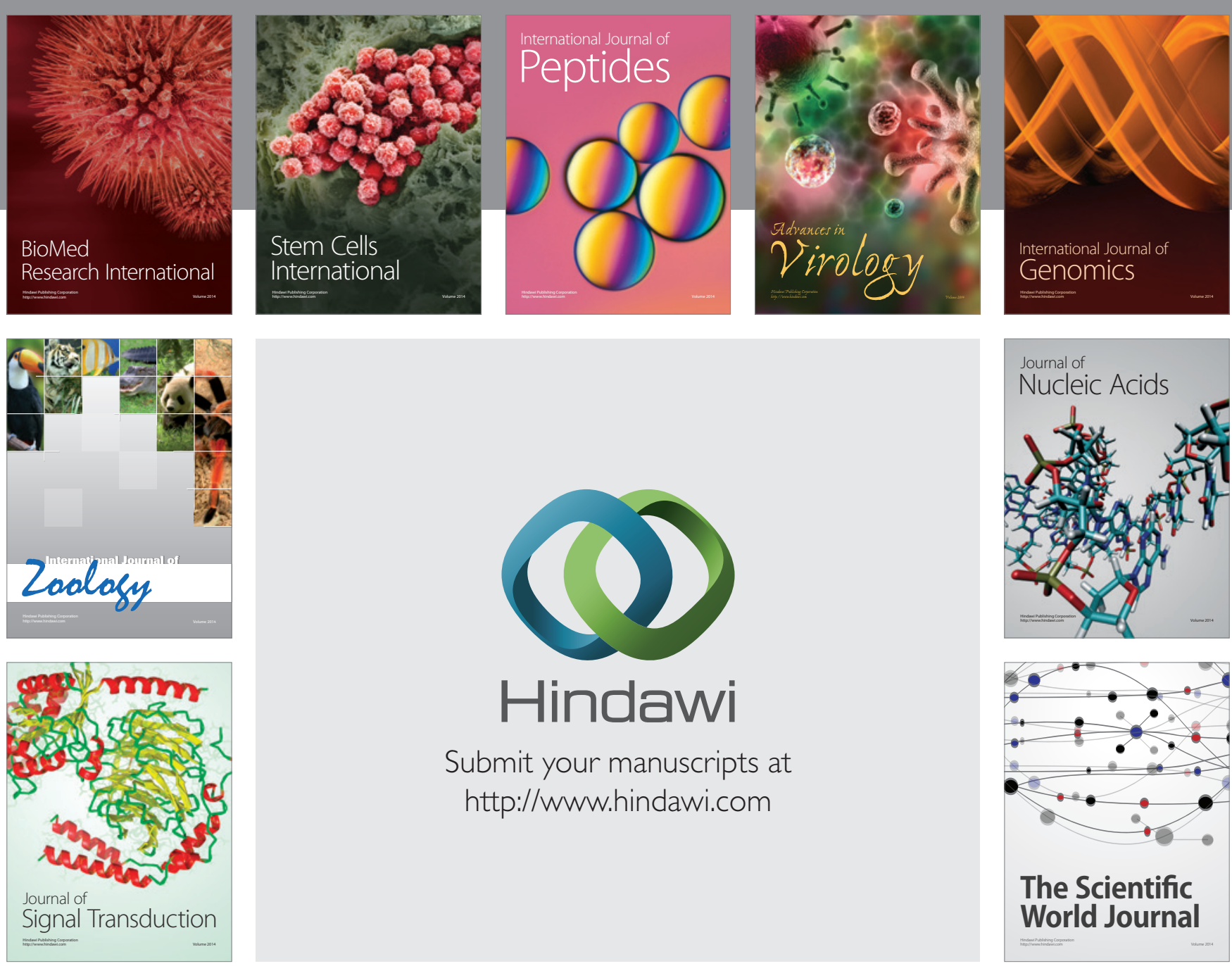

Submit your manuscripts at

http://www.hindawi.com
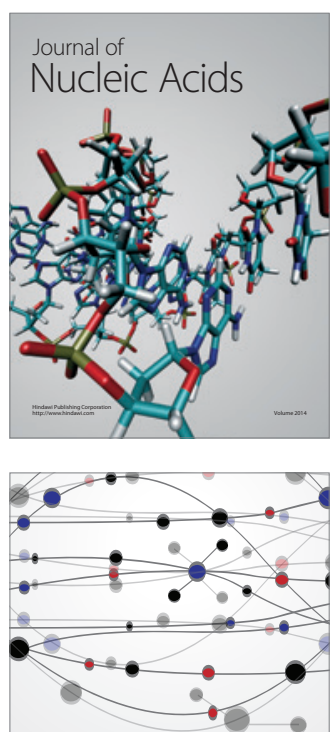

The Scientific World Journal
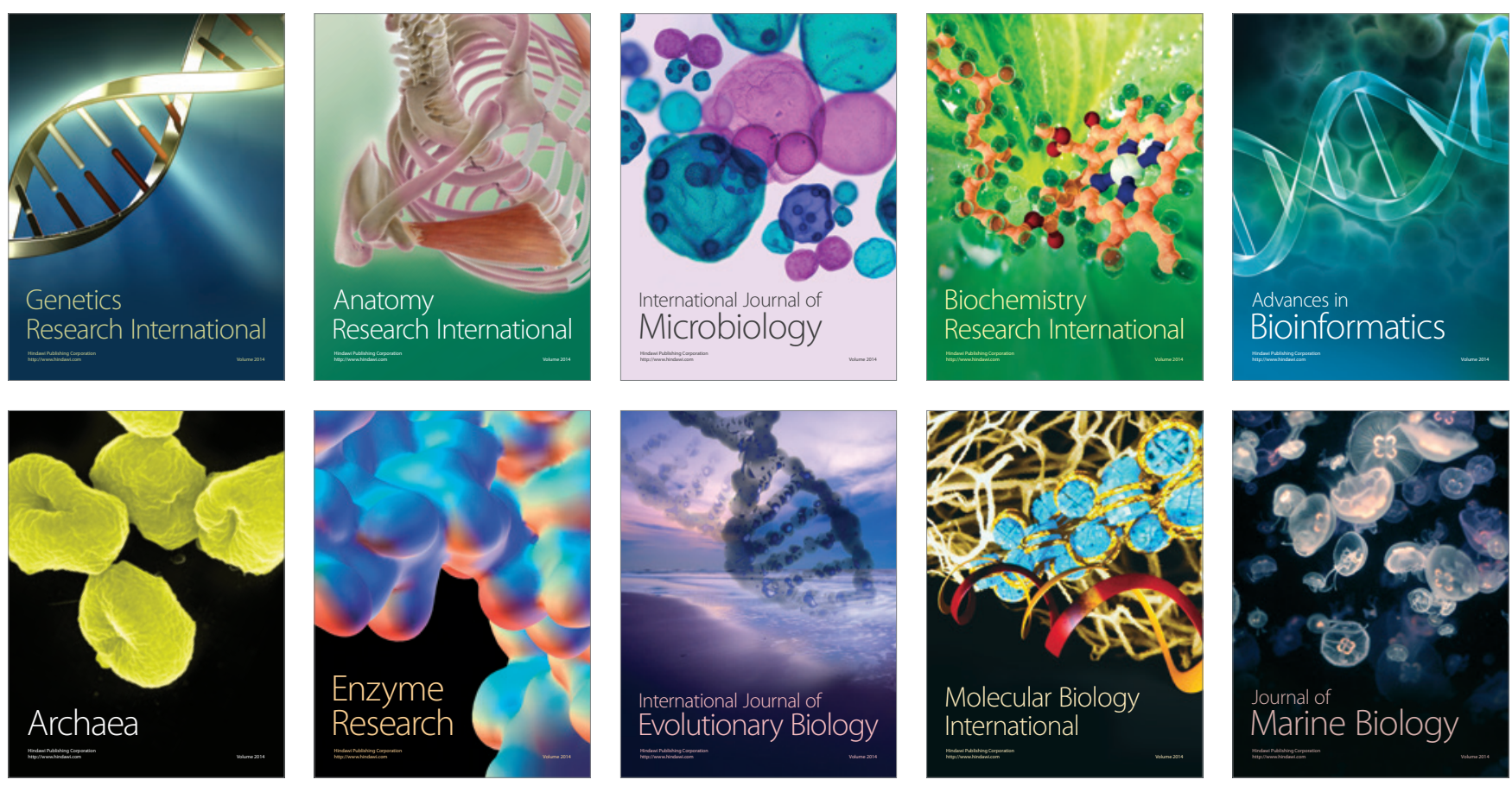